\title{
REVIEW
}

\section{Clostridium difficile Infection in Special High-Risk Populations}

\author{
Alberto Cózar-Llistó · Antonio Ramos-Martinez · Javier Cobo
}

Received: May 19, 2016 / Published online: August 11, 2016

(C) The Author(s) 2016. This article is published with open access at Springerlink.com

\begin{abstract}
Antibiotic use continues to be the most important risk factor for the development of Clostridium difficile infection (CDI) through disruption of the indigenous microbiota of the colon. This factor, together with environmental contamination, makes hospital and other healthcare facilities the perfect breeding ground for the infection. Several groups of patients are exposed to the hospital environment and, at the same time, affected by conditions that can make CDI more prevalent, more severe or make it present a different clinical picture. The list of such

Enhanced content To view enhanced content for this article go to http://www.medengine.com/Redeem/

conditions appears too extensive to be reviewed in a single article. Nevertheless, several groups, including the critically ill, oncological patients, solid organ and hematopoietic transplant recipients, patients with inflammatory bowel disease, patients with kidney disease and pregnant women, have generated more attention and have been studied in more detail. On the other hand, pediatric patients constitute a controversial group because the large number of asymptomatic carriers makes interpretation of clinical findings and diagnostic tests difficult, as is the development of an appropriate approach to treatment. We present an in-depth discussion of CDI in these high-risk populations and we also review the issue of CDI in pediatric patients.
\end{abstract} 18E4F0607C16DFAF.

A. Cózar-Llistó · A. Ramos-Martinez Infectious Diseases Unit, Internal Medicine Department, Hospital Universitario Puerta de Hierro, Majadahonda, Madrid, Spain

A. Cózar-Llistó

e-mail: acozarll@gmail.com

A. Ramos-Martinez

e-mail: aramosm@salud.madrid.org

J. Cobo $(\bowtie)$

Infectious Diseases Service, Hospital Universitario Ramón y Cajal, IRYCIS, Carretera de Colmenar Viejo Km 9.1, 28034 Madrid, Spain

e-mail: javier.cobo@salud.madrid.org
Keywords: Children; Clostridium difficile; units; Kidney diseases; Neoplasms; Pregnancy; Transplantation

\section{INTRODUCTION}

Clostridium difficile infection (CDI) is a health problem of great magnitude due to its Inflammatory bowel disease; Intensive care 
increasing incidence and its elevated morbidity and mortality [1]. It is caused by an anaerobic bacterium capable of proliferating in the intestine and, under certain circumstances, damaging the mucosa by producing toxins.

Antibiotic use continues to be the most important risk factor for the development of C. difficile infection (CDI) through disruption of the indigenous microflora of the colon [2]. Environmental contamination constitutes another relevant risk factor determining healthcare facilities to became the perfect breeding ground for the infection [3].

The main manifestations of this infection are diarrhea and abdominal pain that can also be present in patients with other infections (Salmonella, E. coli, norovirus, etc.), suffering from inflammatory diseases or receiving certain drugs [4].

Certain populations have generated increased attention due to a higher incidence of this disease, to suffering from a more severe disease or to presenting greater difficulty in the interpretation of diagnostic tests because of the existence of other common causes of diarrhea.

The aim of this review is to deepen the knowledge of the peculiarities of this infection in relevant populations such as critically ill patients, oncological patients, hematopoietic stem cell and solid organ transplant recipients, patients with inflammatory bowel disease, patients with renal diseases, pregnant women and children.

To perform this review, original articles, meta-analysis and reviews have been considered. We searched the PubMed database for English language references published from 1980 to 2016 crossing the terms: "Clostridium difficile" or "Pseudomembarnous colitis" with "Intensive Care, Units", "Critically Illness", "Hematologic Neoplasms", "Transplantation", "Inflammatory Bowel Disease", "Kidney Failure,
Chronic renal failure", "Pregnancy", "Child" and "Children".

This article is based on previously conducted studies and does not involve any new studies of human or animal subjects performed by any of the authors.

\section{CRITICALLY ILL PATIENTS WITH CDI}

CDI in patients admitted to an intensive care unit (ICU) represents an important problem due to its high prevalence and high rate of complications [5]. It is estimated that around $11 \%$ of episodes of diarrhea in ICU patients are due to CDI. However, CDI incidence may differ between countries, as highlighted in a recent multicenter study from Spain, which showed a low rate of CDI in ICU patients [6]. This infection may determine a higher length of ICU and hospital stay, and a higher overall mortality rate that can reach $30 \%$ [5]. One study revealed that patients with CDI in the ICU also had a higher risk of complications such as shock and need for surgery [7]. Bouza et al. observed that patients admitted to the ICU due to CDI presented a much more complicated evolution than CDI episodes developed during an ICU stay [8]. Factors associated with a complicated course were a high Simplified Acute Physiology Score (SAPS II), high Sequential Organ Failure Assessment (SOFA) score, and hypoalbuminemia at the onset of CDI [8].

This group may present multiple CDI risk factors which include: comorbidities (such as renal failure and diabetes mellitus) immunosuppression, enteral nutrition, broad-spectrum antibiotics, proton-pump inhibitor administration and steroid treatment [5]. Although classical studies have shown $C$. difficile colonization as a protective factor for development of CDI, a recent study has found 
that C. difficile colonization before ICU admission constitutes an independent risk factor for CDI during ICU stay [9]. Further studies are necessary to confirm these findings and to establish its potential implications.

Severe colitis may present with fever, abdominal pain and distension. In fact, up to $20 \%$ of patients with CDI in the ICU can present ileus without diarrhea which complicates the diagnosis of this infection $[10,11]$. Analytical findings, such as leukocytosis, bandemia and increased serum lactic dehydrogenase levels, may lead to suspicion of CDI in these patients [12]. It is remarkable that an elevated proportion of these patients (up to 25\%) are diagnosed by the presence of pseudomembranes detected through endoscopy or other medical imaging techniques [5]. Furthermore, critically ill patients have a higher risk of CDI recurrence, especially if other risk factors, such as Chronic Obstructive Pulmonary Disease, prior CDI during the previous year, prolonged ICU stay and ICU acquired infection, are present [13].

As in other patient groups, treatment of CDI in the critically ill depends on the severity of the infection [11, 14]. If oral medication is not suitable, administration of intracolonic vancomycin should be considered [11]. In a small study that included patients with CDI, Rokas et al. observed higher survival using combination therapy with oral vancomycin and intravenous metronidazole in comparison to oral vancomycin [15]. Nevertheless, the study was uncontrolled and causes of mortality were not addressed. Pivotal clinical trials of fidaxomicin excluded critically ill patients; however, some reports of limited experience with this drug have recently been published, including the use of crushed tablets administered by nasogastric tube [16-18]. Fecal microbiota transplantation (FMT) can also be considered in patients who do not respond to antibiotics against $C$. difficile [19]. Surgical consultation should be carried out in patients with extensive colitis and unfavorable evolution. Up to $20 \%$ of patients with CDI in the ICU may require colectomy or other surgical procedures [20], such as diverting loop ileostomy and colonic lavage [21, 22]. Early surgery can reduce mortality and may be more beneficial in patients aged 65 years or more, the immunocompetent, and those with leukocytosis or a moderate serum lactate increase [23].

Finally, it should be pointed out that antibiotic stewardship programs and specific infection control measures can reduce the incidence and severity of CDI in these patients [5].

\section{INFECTION IN ONCOLOGICAL PATIENTS}

Oncological patients suffer high rates of CDI due to the frequent presence of risk factors such as recurrent hospitalizations, immunosuppression, antibiotic use (either for prophylactic or therapeutic purposes), chemotherapy and the use of enteral and parenteral nutrition [24]. Despite the suggestion that patients with gastrointestinal tumors have a lesser predisposition to CDI and that patients with breast cancer are more prone to this infection, up to now, no clear relationship between the type of cancer and the risk of CDI has been described [25]. Similarly, some chemotherapy drugs, such as platinum-based agents, taxanes and DNA-topoisomerase inhibitors, have been reported to be more related to CDI than others [26]. However, other studies did not find that any specific chemotherapy drug was especially related to a higher risk of CDI [25]. The pathogenesis of chemotherapy-related CDI is 
not well understood. One suggested mechanism is chemotherapy-mediated fecal microbiota disruption, which creates an environment that is appropriate for $C$. difficile growth [26]. Other possible mechanisms are inflammatory changes in the intestinal mucosa, a decrease in $C$. difficile toxin deterioration and cancer-related immunological changes that could predispose patients to CDI [27-29].

In these patients, diarrhea is the most common clinical manifestation of CDI, together with fever and abdominal pain, as in other groups [25]. Moreover, CDI can require a wide-ranging differential diagnosis because either chemotherapy drugs or other intestinal pathogens could also cause diarrhea. Neutropenia is common in oncological patients; therefore, it is very important to consider that white cell counts might not be appropriate for evaluating the severity of CDI in this group [26].

Treatment of CDI in oncological patients is similar to other groups, but could be complicated by general deterioration, the presence of mucositis and chemotherapy-related nausea. The recurrent CDI rate in oncological patients is similar to the general population [30]. Nevertheless, the impact of CDI can be significant since it may result in the delay or dose reduction of chemotherapy and/or radiotherapy in some patients [24, 25].

Due to the complex physiopathology of CDI in oncological patients, broader prospective studies are needed to explore the risk factors and behavior of this infection in this group.

\section{INFECTION \\ IN HEMATOLOGICAL PATIENTS}

The annual incidence of CDI in these patients fluctuates between $5 \%$ and $20 \%$, which is consistent with the especial susceptibility to infection of hematopoietic stem cell transplant (HSCT) recipients [31]. Higher rates of CDI in allogeneic HSCT recipients may be due to a higher concurrence of the main risk factors for CDI in this population: prolonged hospitalization, gastrointestinal mucosa damage due to chemotherapy drugs, antibiotics, radiotherapy and gastrointestinal graft-versus-host disease (GvHD) [31, 32]. However, the relationship between CDI and GvHD is complex because CDI may increase the risk of GvHD during the first year after infection, which suggests that microbial antigenicity and/or the patient's response to the infection may be involved in its pathogenesis [26, 31].

An increased proportion of CDI episodes appear within the first weeks after transplant [26]. This fact, together with the use of conditioning chemotherapeutic regimens, suggests that $C$. difficile colonization prior to transplant has a relevant role in a large number of these patients [31]. The frequency of pseudomembranes is low in hematological patients, which may be related to their limited inflammatory response due to immunosuppression, and the possible detection of $C$. difficile carriage in those suffering from other causes of diarrhea [33, 34]. Distinguishing between CDI and other causes of diarrhea, such as conditioning chemotherapeutic drugs, GvHD and cytomegalovirus infection, presents an important diagnostic difficulty in these patients [31, 32]. It should be considered that a positive $C$. difficile test, especially the polymerase chain reaction (PCR), does not always confirm that this pathogen is the cause of the diarrhea and that it may simply represent colonization in a patient presenting with diarrhea due to another cause [35].

Recurrent CDI appears in approximately $20 \%$ of these patients, similar to the general 
population [31]. In one study of CDI in allogeneic HSCT recipients, Mani et al. found exposure to antibiotics to be the unique risk factor for recurrence [32]. This study did not reveal any relationship between GvHD and recurrence as was observed in a previous study [31].

Treatment of CDI in hematological patients is similar to other groups and is based on the severity of infection. Parmar et al. did not observe any differences in response to vancomycin or metronidazole [36]. Nevertheless, considering the frequent presence of metallic taste, mucositis and nausea in patients treated with metronidazole, vancomycin is preferred in oncohematological patients [26]. Finally, due to the possibility of sepsis in neutropenic and other immunocompromised patients, probiotics should be used with caution [26].

HSCT recipients are especially vulnerable to infection and are at higher risk of CDI. Further investigation is required to optimize diagnostic algorithms and treatment options in these patients.

\section{IN THE SOLID ORGAN TRANSPLANT RECIPIENT}

CDI is a relevant problem in solid organ transplant (SOT) [37]. It is estimated that the risk of CDI in this group is up to five times higher than in other patients, and is related to the frequent exposure to common risk factors for CDI, such as hospital environment, antibiotic and immunosuppressive therapies $[37,38]$.

Paudel et al. estimated a CDI prevalence of $7.4 \%$ in SOT patients [38]. This meta-analysis demonstrated that liver and lung transplant patients, as well as multiorgan recipients, tended to have a higher rate of CDI compared to kidney transplant recipients. Most cases of
CDI in these patients are diagnosed during the early postoperative period and are due to greater exposure to the above-mentioned risk factors during this time [38]. CDI in SOT patients is also associated with higher mortality, more hospital readmissions and admissions to intensive care units (ICU), longer in-hospital stay, higher costs and worse transplant outcomes [37].

This group presents diagnostic difficulties because diarrhea is a very common complication in SOT patients, and can be caused by infectious and non-infectious conditions. Immunosuppressive drugs themselves are a frequent cause of non-infectious diarrhea, with $C$. difficile, cytomegalovirus and norovirus being the most frequent infectious causes [39].

Knowledge about complications and mortality in this group is limited. Some studies maintain that SOT recipients with CDI have longer in-hospital stay, greater in-hospital mortality and higher costs [40, 41]. Similarly, CDI has been related to graft dysfunction and a higher risk of other infections (pneumonia, cytomegalovirus) [41]. However, complicated CDI has only been observed in $5 \%$ of these patients [42].

With respect to treating CDI, there are no specific recommendations for this group of patients. Due to their frequent exposure to antibiotics, it is especially important to consider discontinuing predisposing drugs of this type. Initial treatment in mild and moderate cases of CDI in SOT recipients has been based on oral metronidazole [43]. As for other groups, oral vancomycin is the treatment of choice in severe CDI. Due to their potential interactions, adequate plasma level monitoring of immunosuppressive drugs is crucial during treatment with antibiotics, including metronidazole [44]. It is remarkable that some patients tend to present leukopenia after 
transplant, which may mean a misclassification of CDI severity due to the inability to develop leukocytosis [45].

Fidaxomicin is a novel macrocyclic antibiotic that has demonstrated a similar clinical response but with a lower CDI recurrence rate than oral vancomycin $[46,47]$. One study revealed no differences in cure rates of CDI for fidaxomicin and conventional treatment in SOT and hematopoietic stem cell transplant patients, but lower selection of vancomycin-resistant enterococci among those treated with this novel agent [48]. This study also reported that patients treated with fidaxomicin did not demonstrate any significant variations between plasma concentrations of immunosuppressive drugs.

Surgical consultation should be carried out in the cases of patients who do not progress favorably because the incidence of fulminant colitis may be higher in SOT recipients [43]. In fact, Boutros et al. showed good outcomes when colectomy was performed early in patients with complicated CDI [39, 49]. In patients with multiple recurrences, treatment can be based on oral vancomycin with a pulse-dosing or prolonged tapering schedule, with similar results [39]. There is little experience with fecal bacteriotherapy in SOT recipients. Fecal microbiota transplantation has been employed in some cases with good outcomes and no relevant side effects [50]. However, these patients are not usually considered candidates for these therapies due to their theoretical (but unproved) potential for infection [43].

Despite the special clinical features of SOT recipients, the risk of recurrent CDI is similar to other patient groups (8\% and 20\%) [38, 39]. Comorbidity, immunosuppression, long hospital admission and frequent antibiotic use are common risk factors associated to recurrent
CDI in SOT recipients [51, 52]. Screening for hypogammaglobulinemia is advisable in CDI as this is a predisposing and treatable factor [53].

In summary, CDI is a relevant problem in SOT recipients and with an increasing incidence. This infection increases mortality and graft loss rates in these patients. Due to the above, special efforts are considered essential to adequately prevent, diagnose and treat CDI in SOT patients.

\section{INFECTION IN PATIENTS WITH INFLAMMATORY BOWEL DISEASE}

CDI is diagnosed more frequently in patients with inflammatory bowel disease (IBD) than in the general population [54, 55], and represents an important burden on patients with IBD because of the greater healthcare costs and increased need for surgical treatment [56]. Detection of this infection could be more difficult in these patients, because symptoms, such as abdominal pain and diarrhea, could be due to an exacerbation of IBD or to other infectious causes such as cytomegalovirus colitis [57]. Therefore, CDI screening is crucial in patients supposedly suffering from IBD exacerbation.

CDI in patients with IBD tends to affect younger patients and to be community acquired, which is in line with the great ribotype diversity observed in community-acquired CDI as in many IBD patients in clinical remission colonized by $C$. difficile $[57,58]$. It seems that patients with ulcerative colitis have a higher risk of CDI than patients with Crohn's disease, which may be related to the more common and extensive involvement of the colon in patients with ulcerative colitis [59].

Patients with IBD are characterized by receiving immunosuppressive and steroid 
treatment which, in those with a deteriorated gastrointestinal tract barrier function, may impair immune response to this infection [56, 60-62]. These patients often require hospitalization and frequently undergo endoscopic and surgical procedures which also increase the risk of CDI [56, 60-62]. Another issue is that some studies did not show a clear relationship between CDI infection with previous exposure to antibiotics in IBD patients compared to others $[54,55]$. On the other hand, the influence of proton pump inhibitors (PPI) on the development of CDI in these patients is considered uncertain. Some authors did not find any correlation between treatment with PPI and CDI [55], whereas a clear relationship was demonstrated by others [58].

Clinical manifestations of CDI in patients with IBD vary from asymptomatic colonization to severe forms that can be life-threatening. Although it is generally considered that patients with IBD have more severe forms of CDI and higher rates of complications [54, 59], some authors did not find this relationship [58]. According to current knowledge, it cannot be definitely assumed that the prognosis of CDI infection in IBD patients is worse in relation to length of in-hospital stay, colectomy and mortality. A retrospective study of prognostic factors revealed that a plasmatic albumin concentration under $3 \mathrm{~g} / \mathrm{dL}$ is an independent predictor of severe outcomes of CDI in patients with IBD [63]. Atypical presentations of CDI are frequent in patients with IBD (e.g., bloody diarrhea in a young patient with no previous history of hospital admission, ileum involvement in those patients with previous colectomy and "infectious" pouchitis in patients with an ileo-anal reservoir). In addition, endoscopy rarely reveals pseudomembranes and is frequently ineffective for distinguishing between IBD exacerbation and CDI $[54,55,60]$. It appears that IBD patients do not have a high risk of recurrence [64].

There are no specific recommendations for the treatment of CDI in this group. Although it is unclear that CDI in IBD patients is more severe, some authors suggest the initial use of vancomycin due to the presumed high risk of complications in them [59]. Until now, no study has analyzed the use of fidaxomicin for the treatment of CDI in IBD patients [65]. It seems that FMT is not as effective in the treatment of IBD as for the treatment of CDI [66]. One study that analyzed the use of FMT for the treatment of recurrent CDI in patients with IBD demonstrated that this therapy was less effective in clearing recurrent CDI if the patient suffered from IBD. Furthermore, around 25\% of patients with IBD had a disease flare after FMT [67].

There are no clear recommendations with respect to the maintenance or modification of IBD treatment during CDI. One multicenter retrospective study revealed that patients treated with immunomodulators plus active treatment against CDI more frequently presented in-hospital megacolon, bowel perforation, hemodynamic shock or respiratory failure, and the primary composite outcome was death or colectomy within 3 months of admission [68]. However, it should be noted that the use of immunomodulators could be a confounding factor due to a possible selection of patients with worse clinical state.

In summary, due to the elevated rate of asymptomatic carriers, the difficulties related to clinical and endoscopic diagnosis, as well as the possible higher risk of complications and mortality among these patients, it is important that physicians be on the alert for CDI and compatible clinical findings in patients with IBD. 


\section{IN PATIENTS WITH RENAL DISEASE}

Between about $8 \%$ and $12 \%$ of the world's population suffer from some form of chronic kidney disease (CKD) [69]. Since patients diagnosed with $\mathrm{CKD}$ are more frequently exposed to the hospital environment, and also frequently receive antibiotics, a higher incidence of CDI can be expected in this group.

Perhaps the largest investigation addressing the incidence of CDI among patients with CKD was the study published in 2012 by Keddis et al. By using the large National Hospital Discharge Surveys database, they were able to calculate the incidence of CDI in more than 160 million hospitalizations. They found that the incidence of CDI in patients with CKD doubles the incidence of CDI in the general population and that the effect was particularly high among patients undergoing dialysis [70].

Moreover, a recent meta-analysis confirmed that the incidence of CDI is higher in patients with kidney disease (RR 1.95; 95\% CI 1.81-2.10). The risk even increases in the case of end-stage renal failure (RR 2.63; 95\% CI 2.04-3.38) [71]. Gastric acid suppression or microorganism overgrowth caused by intestinal dysmotility is frequently observed in CKD patients; this may also contribute to an increased risk of CDI [72]. Clinicians should be especially prudent when prescribing antibiotics for these patients, not only due to the known increased toxicity of several antimicrobials in patients with renal failure but also due to the increased risk of CDI.

Does CDI cause poorer outcomes in patients with CKD? Pant et al. compared costs, mortality and length of stay (LOS) in patients with end-stage renal disease and CDI with hospitalized patients with end-stage renal disease without CDI. They found that CDI increased LOS by 9 days, raised costs by
US\$68,000, and doubled mortality [73]. A recent systematic review based on 4 cohort studies quantified that CDI increased mortality among patients with chronic renal failure (CRF) (RR 1.73; 95\% CI 1.39-2.15), and especially in those with end-stage renal disease (RR 2.15; 95\% CI 2.07-2.23) [74]. Some authors have drawn attention to the risk of missing CDI in patients with CRF presenting without diarrhea (ileus). Nevertheless, it is unknown whether these atypical clinical presentations are more frequent among patients with CRF [75]. There is no evidence to suggest that hemodialysis patients with CDI have a worse prognosis; this is perhaps due to the fact that normally they are continuously checked and monitored [70].

A more extensive systematic review to evaluate the outcomes of CDI among patients with CRF or end-stage renal disease has recently been published. The results confirmed a higher relative risk for severe or severe-complicated CDI (1.51; 95\% CI 1.00-2.28), for risk of mortality $(1.76 ; 95 \%$ CI $1.26-2.47)$, and for recurrence $(2.73 ; 95 \%$ CI 1.36-5.47) [76]. One classic study pointed out a higher risk for recurrent CDI [77], which was confirmed by a previously mentioned meta-analysis [71]. In fact, several clinical prediction tools include renal function in their scoring system [78, 79].

Recent studies have shown a better and quicker response to vancomycin than to metronidazole, which is more evident in severe forms of CDI [80]. Oral vancomycin remains almost unabsorbed and prospective studies have confirmed that a dosage of $125 \mathrm{mg}$ four times per day is not associated with detectable vancomycin levels in serum [81]. Nevertheless, detectable levels of vancomycin in patients with CDI have been reported in those treated with high dosages [82], which could be important in patients with renal failure and especially those with a certain 
renal functional reserve. To answer this question, Pettit et al. studied a group of 85 patients treated with vancomycin. They found detectable levels of vancomycin in $68 \%$. However, only $17.6 \%$ had levels above $2.5 \mathrm{mg}$ / L. These levels were associated with renal disease, the use of enemas and the presence of gastrointestinal disease [83]. In short, conventional doses may be safely used in patients with CRF. In exceptional cases, when using vancomycin enemas or in patients with concomitant intestinal diseases, vancomycin serum concentration determinations would be advisable.

Since patients with renal disease were allowed to participate in pivotal clinical trials that compared fidaxomicin with vancomycin, a subanalysis of patients with CKD included in these trials provided interesting prospective information. Response to therapy was inferior and rates of recurrence were higher in patients with stage 4 or $5 \mathrm{CRF}$. Those treated with fidaxomicin presented fewer recurrences than those treated with vancomycin (absolute risk reduction $10 \%$ for patients in stage $2,11.6 \%$ for patients in stage 3 and $19.6 \%$ in patients in stage 4) [84]. In fact, the use of fidaxomicin in persons with CRF could be cost-effective [85]. Plasma fidaxomicin concentrations are very low and are not affected by renal function [86].

\section{IN PREGNANT WOMEN}

It is known that the acquisition of $C$. difficile in neonates occurs regularly during the first few weeks of life. Although the environment seems to be the principal source of such colonization, it has been shown that mothers are sometimes carriers of $C$. difficile in proportions ranging between $11 \%$ and 18\% [87]. Because pregnant women are young and healthy people, they could be considered at very low risk for CDI.
However, in 1984, a small outbreak of pseudomembranous colitis was reported in women that had received antibiotic prophylaxis for caesarean section and shared the same ward and delivery room [88]. It could obviously have been an isolated event. In fact, a review of CDI cases in the obstetrical and gynecological departments of two hospitals reported the incidence to be as low as $0.02 \%$. Moreover, only a small percentage of the cases were in the obstetric areas [89].

Nevertheless, the description of new cases of severe-complicated CDI in post-partum again drew attention to the possibility of a higher susceptibility to CDI during pregnancy, particularly in peripartum or postpartum women [90, 91]. A survey was carried out among North American infectious disease specialists to better understand the frequency of CDI in pregnancy. Around 9\% of those that responded had attended or had reports of CDI in peripartum women during the previous 6 months. The survey also allowed information to be collected from 55 cases. Thirty-seven per cent of them occurred around the time of labor, and there were cases during all three trimesters. Forty-three developed some complication, 10 presented recurrences and 5 toxic megacolon (3 requiring colectomy). There were also three fetal losses [92].

Using Nationwide Inpatient Sample data, Kuntz and colleagues were able to calculate the true incidence of CDI around the time of labor. They crossed data service records in obstetrics with diagnoses of CDI between 1998 and 2006. The study sample included 1706 cases. The incidence of CDI in women hospitalized for childbirth increased from around 0.4 per 10,000 to 0.6 per 10,000 , in parallel with that of the general population, which was 40 per 10,000 to 80 per 10,000 during the same period. Most (67\%) cases were 
of women who underwent caesarean delivery [93].

Is CDI really more severe in pregnant women? Of course, some bias could exist since severe cases are probably reported more frequently. Nevertheless, during a large outbreak that occurred in an obstetric department, 16 out of 20 women presented with fever and 9 with leukocytosis. These percentages of systemic response are not so common among the general population and have also been reported in other series [94, 95].

In pregnant women, the Th1 response is replaced by a Th2 response. Since $C$. difficile-induced colitis is characterized by an influx of neutrophils into the colonic mucosa, which is mediated by a Th1 immune response, it has been hypothesized that the immunoregulation associated with pregnancy increases the risk of CDI by downregulating the Th1 response that is necessary to control the disease [96].

In summary, although the incidence of CDI in pregnant women has not been specifically compared with CDI incidence in healthy people of the same age, they seem to show a substantial risk of CDI due to their exposure to antibiotics and the hospital environment (both conditions occurring in cases of caesarean section deliveries), and the immune changes associated to pregnancy. Moreover, CDI in pregnant women can cause systemic manifestations and pose the risk of complications for both the mother and the fetus.

\section{INFECTION IN PEDIATRIC PATIENTS}

CDI has been thoroughly studied in adults, but not in children, in whom concern about this infection has risen during the last few years [97]. Currently, CDI is considered a relevant problem in children, and one which can be occasionally associated with colectomy, increased length of hospital stay and mortality [98].

Children under 1 year of age are typically excluded from being defined as CDI due to the high rate of asymptomatic carriers, the absence of toxin A/B receptors in their immature colon, and the high prevalence of diarrhea due to other, mainly viral, etiologies [99]. One study revealed that the isolation of toxigenic $C$. difficile strains in feces from children less than 2 years of age has no relationship with the severity of diarrhea or healing, regardless of whether or not the patient was treated for $C$. difficile [100]. Considering the previous evidence, the American Academy of Pediatrics does not recommend microbiological testing in children less than 1 year of age unless they present compatible clinical findings and specific gastrointestinal motility disorders (such as Hirschsprung's disease) or in certain epidemiological contexts (such as outbreaks of CDI). It is also recommended that children between 1 and 3 years of age are first screened for other causes of diarrhea (such as viral infections) [101]. Whatever the case may be, early diagnosis is crucial for a favorable evolution in high-risk groups (especially the immunocompromised and patients with IBD) [102].

Common risk factors for CDI in children are age 1-4 years old, prior antibiotic treatment (particularly cephalosporins, and penicillins), and exposure to a hospital environment $[103,104]$. However, antibiotic exposure is not firmly associated to community-acquired CDI cases [105]. The relationship between chronic treatment with PPI and the risk of CDI has been shown in most, but not all, studies [104, 106, 107]. Children with inflammatory bowel disease (IBD) also have a higher risk of CDI and asymptomatic $C$. difficile colonization 
[103]. In addition, children that receive solid organ transplantation and hematopoietic stem cell transplantation have a higher risk of CDI $[97,104]$. The placement of gastrointestinal feeding devices has been related to community-associated CDI in children [105]. As in other patients, the diagnosis of CDI in children is based on compatible clinical findings and detection of $C$. difficile in feces by microbiological techniques (enzyme immunoassay, polymerase chain reaction, microbial culture, etc.) if no other etiologies are present [99].

Severe complications of CDI, especially fulminant CDI and pseudomembranous colitis, are not commonly observed in children. The clinical presentation of CDI in these patients consists in most cases of mild to moderate diarrhea [101, 102, 108, 109]. To improve patient treatment, several authors have recommended specific severity criteria for children [110, 111]. In our opinion, the criteria defined by Kim et al. are the most appropriate because they take into account that severity in pediatric CDI is frequently overestimated using adult criteria [111]. They considered that a CDI episode is severe if there are one or more complications: e.g., ICU admission, toxic megacolon, pseudomembranous colitis, intestinal perforation or surgery, or two or more laboratory/clinical indicators, such as fever, hematochezia, elevated white blood cell count, low albumin, or high creatinine. Fortunately, the hypervirulent strain (027) has only been detected infrequently in pediatric patients [99, 111].

Regarding the treatment of CDI in children, guidelines recommend, as a first step and wherever possible, discontinuation of the antibiotic that triggered the CDI. With respect to treatment, oral metronidazole is recommended for children with moderate CDI and the first recurrence, and oral vancomycin (with or without intravenous metronidazole) for severe CDI and a second recurrence [101]. Although there are few studies on the subject, fecal microbiota transplantation has been shown to be effective in children with recurrent CDI [106]. As in adults, microbiological analysis at the end of treatment is inadvisable because many patients continue to present positive toxin determinations [101].

Recurrent episodes are somewhat more frequent in adults than in children [99]. Relevant risk factors for recurrence in children are malignancy, recent surgery, number of antibiotic exposition by class and IBD [107, 112].

The increasing incidence of CDI in hospitalized children [97], difficulties in diagnostic test interpretation due to high rates of asymptomatic carriers [102], and high risk of CDI in specific subgroups (IBD, solid organ and hematopoietic stem cell transplantation, etc.) $[97,103,104,112]$ substantiate the requirement for enhanced investigation into more appropriate diagnostic algorithms and new treatments that take into account the special features of the intestinal microbiome in children [99].

\section{CONCLUSION}

Clostridium difficile infection is a health problem of great relevance. Knowledge of the particularities of CDI in different populations may be relevant in order to better assess the risk of this disease and establish suitable prevention measures.

The diagnosis of CDI in patients with diseases that are complicated by diarrhea, such as IBD or hematopoietic transplant recipients, 
represents a clinical challenge. Other conditions (pregnant women, SOT and CRF patients) deserve a special watchfulness for a higher risk of complications.

Finally, many aspects of the relevance, impact, pathogenesis and management of CDI in the special populations addressed in this review remain to be elucidated and should be the subject of future studies.

\section{ACKNOWLEDGMENTS}

No funding or sponsorship was received for this study or publication of this article. All named authors meet the International Committee of Medical Journal Editors (ICMJE) criteria for authorship for this manuscript, take responsibility for the integrity of the work as a whole, and have given final approval for the version to be published. The authors thank Martin Hadley-Adams for assisting with the English language and preparation of the manuscript.

Disclosures. Alberto Cózar declares no conflicts of interest. Antonio Ramos has received speaker honorariums from Astellas and MSD. Javier Cobo has received speaker honorariums from Astellas and consultancy honorariums from Astellas and MSD.

Compliance with Ethics Guidelines. This article is based on previously conducted studies and does not involve any new studies of human or animal subjects performed by any of the authors.

Open Access. This article is distributed under the terms of the Creative Commons Attribution-NonCommercial 4.0 International License (http://creativecommons.org/licenses/ by-nc/4.0/), which permits any noncommercial use, distribution, and reproduction in any medium, provided you give appropriate credit to the original author(s) and the source, provide a link to the Creative Commons license, and indicate if changes were made.

\section{REFERENCES}

1. McDonald LC, Owings M, Jernigan DB. Clostridium difficile infection in patients discharged from US short-stay hospitals, 1996-2003. Emerging Infect Dis. 2006;12:409-15.

2. Slimings C, Riley TV. Antibiotics and hospital-acquired Clostridium difficile infection: update of systematic review and meta-analysis. J Antimicrob Chemother. 2014;69:881-91.

3. Weber DJ, Anderson DJ, Sexton DJ, Rutala WA. Role of the environment in the transmission of Clostridium difficile in health care facilities. Am J Infect Control. 2013;41:S105-10.

4. Longo DL, Leffler DA, Lamont JT. Clostridium difficile Infection. N Engl J Med. 2015;372:1539-48.

5. Karanika S, Paudel S, Zervou FN, Grigoras C, Zacharioudakis IM, Mylonakis E. Prevalence and clinical outcomes of Clostridium difficile infection in the intensive care unit: a systematic review and meta-analysis. Open Forum Infect Dis. 2016; 3:ofv186-10.

6. Alvarez-Lerma F, Palomar M, Villasboa A, et al. Epidemiological study of Clostridium difficile infection in critical patients admitted to the Intensive Care Unit. Med Intensiv. 2014;38:558-66.

7. Sabau L, Meybeck A, Gois J, et al. Clostridium difficile colitis acquired in the intensive care unit: outcome and prognostic factors. Infection. 2013;42:23-30.

8. Bouza E, Rodríguez-Créixems M, Alcalá L, et al. Is Clostridium difficile infection an increasingly common severe disease in adult intensive care units? A 10-year experience. J Crit Care. 2015;30:543-9.

9. Tschudin-Sutter S, Carroll KC, Tamma PD, et al. Impact of toxigenic clostridium difficile colonization on the risk of subsequent C. difficile infection in intensive care unit patients. Infect Control Hosp Epidemiol. 2015;36:1324-9. 
10. Sheth SG, LaMont JT. Gastrointestinal problems in the chronically critically ill patient. Clin Chest Med. 2001;22:135-47.

11. Riddle DJ, Dubberke ER. Clostridium difficile infection in the intensive care unit. Infect Dis Clin North Am. 2009;23:727-43.

12. Wanahita A, Goldsmith EA, Marino BJ, Musher DM. Clostridium difficile infection in patients with unexplained leukocytosis. Am J Med. 2003;115:543-6.

13. Jasiak NM, Alaniz C, Rao K, Veltman K, Nagel JL. Recurrent clostridium difficile infection in intensive care unit patients. Am J Infect Control. 2016;44:36-40.

14. Cohen SH, Gerding DN, Johnson S, et al. Clinical practice guidelines for clostridium difficile infection in adults: 2010 update by the Society for Healthcare Epidemiology of America (SHEA) and the Infectious Diseases Society of America (IDSA). Infect Control Hosp Epidemiol. 2010;31:431-55.

15. Rokas KEE, Johnson JW, Beardsley JR, Ohl CA, Luther VP, Williamson JC. The addition of intravenous metronidazole to oral vancomycin is associated with improved mortality in critically ill patients with Clostridium difficile infection. Clin Infect Dis. 2015;61:934-41.

16. Penziner S, Dubrovskaya Y, Press R, Safdar A. Fidaxomicin therapy in critically ill patients with Clostridium difficile infection. Antimicrob Agents Chemother. 2015;59:1776-81.

17. Tousseeva A, Jackson JD, Redell M, et al. Stability and recovery of DIFICID $((\mathrm{R})$ ) (Fidaxomicin) 200-mg crushed tablet preparations from three delivery vehicles, and administration of an aqueous dispersion via nasogastric tube. Drugs $R$ D. 2014;14:309-14.

18. Maseda E, Hernandez-Gancedo C, Lopez-Tofiño A, Suarez-de-la Rica A, Garcia-Bujalance S, Gilsanz F. Use of fidaxomicin through a nasogastric tube for the treatment of septic shock caused by Clostridium difficile infection in a patient with oral cancer admitted to the Surgical Critical Care Unit. Rev Esp Quimioter. 2013;26:375-7.

19. Fischer M, Sipe BW, Rogers NA, et al. Faecal microbiota transplantation plus selected use of vancomycin for severe-complicated Clostridium difficile infection: description of a protocol with high success rate. Aliment Pharmacol Ther. 2015;42:470-6.

20. Grundfest-Broniatowski S, Quader M, Alexander F, Walsh RM, Lavery I, Milsom J. Clostridium difficile colitis in the critically ill. Dis Colon Rectum. 1996;39:619-23.

21. Neal MD, Alverdy JC, Hall DE, Simmons RL, Zuckerbraun BS. Diverting loop ileostomy and colonic lavage. Ann Surg. 2011;254:423-9.

22. Dela'O CM, Quyyum A, Dumire RD, Simunich TJ, Miller SL, Rodriguez A. Community hospital experience of refractory Clostridium difficile colitis: treatment and efficacy of diverting loop ileostomy and colonic lavage. Am Surg. 2014;80:E247-9.

23. Lamontagne FO, Labb A-C, Haeck O, et al. Impact of emergency colectomy on survival of patients with fulminant Clostridium difficile colitis during an epidemic caused by a hypervirulent strain. Ann Surg. 2007;245:267-72.

24. Hautmann MG, Hipp M, Kölbl O. Clostridium difficile-associated diarrhea in radiooncology: an underestimated problem for the feasibility of the radiooncological treatment? Radiat Oncol. 2011;6:89.

25. Rodríguez Garzotto A, Mérida García A, Muñoz Unceta $\mathrm{N}$, et al. Risk factors associated with Clostridium difficile infection in adult oncology patients. Support Care Cancer. 2015;23:1569-77.

26. Chopra T, Alangaden GJ, Chandrasekar P. Clostridium difficile infection in cancer patients and hematopoietic stem cell transplant recipients. Expert Rev Anti Infect Ther. 2010;8:1113-9.

27. Anand A, Glatt AE. Clostridium difficile infection associated with antineoplastic chemotherapy: a review. Clin Infect Dis. 1993;17:109-13.

28. Loo VG, Bourgault A-M, Poirier L, et al. Host and pathogen factors for Clostridium difficile infection and colonization. $\mathrm{N}$ Engl J Med. 2011;365:1693-703.

29. Bishop KD, Castillo JJ. Risk factors associated with Clostridium difficile infection in adult oncology patients with a history of recent hospitalization for febrile neutropenia. Leuk Lymphoma. 2012;53:1617-9.

30. Cornely OA, Miller MA, Fantin B, Mullane K, Kean $\mathrm{Y}$, Gorbach S. Resolution of Clostridium difficile-associated diarrhea in patients with cancer treated with fidaxomicin or vancomycin. J Clin Oncol. 2013;31:2493-9.

31. Alonso CD, Treadway SB, Hanna DB, et al. Epidemiology and outcomes of Clostridium difficile infections in hematopoietic stem cell transplant recipients. Clin Infect Dis. 2012;54:1053-63. 
32. Mani S, Rybicki L, Jagadeesh D, Mossad SB. Risk factors for recurrent Clostridium difficile infection in allogeneic hematopoietic cell transplant recipients. Bone Marrow Transplant 2016;1-5. Advance online publication, Jan 4, 2016. doi:10.1038/bmt.2015. 311.

33. Nomura K, Fujimoto Y, Yamashita M, et al. Absence of pseudomembranes in Clostridium difficile-associated diarrhea in patients using immunosuppression agents. Scand J Gastroenterol. 2009;44:74-8.

34. Wang MS, Evans CT, Rodriguez T, Gerding DN, Johnson S. Clostridium difficile infection and limitations of markers for severity in patients with hematologic malignancy. Infect Control Hosp Epidemiol. 2013;34:127-32.

35. Polage CR, Gyorke CE, Kennedy MA, et al. Overdiagnosis of Clostridium difficile infection in the molecular test era. JAMA Intern Med. 2015;175:1792-801.

36. Parmar SR, Bhatt V, Yang J, Zhang Q, Schuster M. A retrospective review of metronidazole and vancomycin in the management of Clostridium difficile infection in patients with hematologic malignancies. J Oncol Pharm Pract. 2014;20:172-82.

37. Donnelly JP, Wang HE, Locke JE, Mannon RB, Safford MM, Baddley JW. Hospital-onset Clostridium difficile infection among solid organ transplant recipients. Am J Transplant. 2015;15:2970-7.

38. Paudel S, Zacharioudakis IM, Zervou FN, Ziakas PD, Mylonakis E. Prevalence of Clostridium difficile infection among solid organ transplant recipients: a meta-analysis of published studies. PLoS ONE. 2015;10:e0124483-516.

39. Angarone M, Ison MG. Diarrhea in solid organ transplant recipients. Curr Opin Infect Dis. $2015 ; 28: 308-16$.

40. Pant C, Deshpande A, Gilroy R, Olyaee M, Donskey CJ. Rising incidence of Clostridium difficile related discharges among hospitalized children in the United States. Infect Control Hosp Epidemiol. 2015;37:104-6.

41. Mittal C, Hassan S, Arshad S, et al. Clostridium difficile infection in liver transplant recipients: a retrospective study of rates, risk factors and outcomes. Am J Transplant. 2014;14:1901-7.

42. Pant C, Anderson MP, O'Connor JA, Marshall CM, Deshpande A, Sferra TJ. Association of Clostridium difficile infection with outcomes of hospitalized solid organ transplant recipients: results from the
2009 Nationwide Inpatient Sample database. Transplant Infect Dis. 2012;14:540-7.

43. Dubberke ER, Burdette SD, the AST Infectious Diseases Community of Practice. Clostridium difficile infections in solid organ transplantation. Am J Transplant 2013; 13:42-49.

44. Naderer OJ, Dupuis RE, Heinzen EL, Wiwattanawongsa K, Johnson MW, Smith PC. The influence of norfloxacin and metronidazole on the disposition of mycophenolate mofetil. J Clin Pharmacol. 2005;45:219-26.

45. Hao C, Anwei M, Bing C, et al. Monitoring mycophenolic acid pharmacokinetic parameters in liver transplant recipients: prediction of occurrence of leukopenia. Liver Transplant. 2008; 14:1165-73.

46. Smith EP. Hematologic disorders after solid organ transplantation. Hematol Am Soc Hematol Educ Progr. 2010;2010:281-6.

47. Crook DW, Walker AS, Kean Y, et al. Fidaxomicin versus vancomycin for Clostridium difficile infection: meta-analysis of pivotal randomized controlled Trials. Clin Infect Dis. 2012;55:S93-103.

48. Clutter DS, Dubrovskaya Y, Merl MY, Teperman L, Press R, Safdar A. Fidaxomicin versus conventional antimicrobial therapy in 59 recipients of solid organ and hematopoietic stem cell transplantation with Clostridium difficile-associated diarrhea. Antimicrob Agents Chemother. 2013;57:4501-5.

49. Boutros M, Al-Shaibi M, Chan G, et al. Clostridium difficile colitis. Transplantation. 2012;93:1051-7.

50. Friedman-Moraco RJ, Mehta AK, Lyon GM, Kraft CS. Fecal microbiota transplantation for refractory Clostridium difficile colitis in solid organ transplant recipients. Am J Transplant. 2014;14:477-80.

51. Hsu JL, Enser JJ, McKown T, et al. Outcomes of Clostridium difficile infection in recipients of solid abdominal organ transplants. Clin Transplant. 2014;28:267-73.

52. Gellad ZF, Alexander BD, Liu JK, et al. Severity of Clostridium difficile-associated diarrhea in solid organ transplant patients. Transplant Infect Dis. 2007;9:276-80.

53. Muñoz P, Giannella M, Alcalá L, et al. Clostridium difficile-associated diarrhea in heart transplant recipients: is hypogammaglobulinemia the answer? J Heart Lung Transplant. 2007;26:907-14.

54. Monaghan TM, Cockayne A, Mahida YR. Pathogenesis of Clostridium difficile infection and 
Its potential role in inflammatory bowel disease. Inflamm Bowel Dis. 2015;21:1957-66.

55. Goodhand JR, Alazawi W, Rampton DS. Systematic review: Clostridium difficile and inflammatory bowel disease. Aliment Pharmacol Ther. 2010;33:428-41.

56. Trifan A. Impact of Clostridium difficile infection on inflammatory bowel disease outcome: a review. World J Gastroenterol. 2014;20:11736-8.

57. Clayton EM, Rea MC, Shanahan F, et al. The vexed relationship between Clostridium difficile and inflammatory bowel disease: an assessment of carriage in an outpatient setting among patients in remission. Am J Gastroenterol. 2009;104:1162-9.

58. Ramos-Martínez A, Ortiz-Balbuena J, Curto-García I, et al. Risk factors for Clostridium difficile diarrhea in patients with inflammatory bowel disease. Rev Esp Enferm Dig. 2015;107:4-8.

59. Czepiel J, Biesiada G, Perucki W, Mach T. Clostridium difficile infection in patients with inflammatory bowel disease. Prz Gastroenterol. 2014;3:125-9.

60. Killeen S, Martin ST, Hyland J, O'Connell PR, Winter DC. Clostridium difficile enteritis: a new role for an old foe. Surgeon. 2014;12:256-62.

61. Schneeweiss S, Korzenik J, Solomon DH, Canning $\mathrm{C}$, Lee $\mathrm{J}$, Bressler $\mathrm{B}$. Infliximab and other immunomodulating drugs in patients with inflammatory bowel disease and the risk of serious bacterial infections. Aliment Pharmacol Ther. 2009;30:253-64.

62. Regnault H, Bourrier A, Lalande V, et al. Prevalence and risk factors of Clostridium difficile infection in patients hospitalized for flare of inflammatory bowel disease: a retrospective assessment. Digest Liver Dis. 2014;46:1086-92.

63. Ananthakrishnan AN, Guzman-Perez R, Gainer V, et al. Predictors of severe outcomes associated with Clostridium difficile infection in patients with inflammatory bowel disease. Aliment Pharmacol Ther. 2012;35:789-95.

64. Rodemann JF, Dubberke ER, Reske KA, Seo DH, Stone CD. Incidence of Clostridium difficile Infection in inflammatory bowel disease. Clin Gastroenterol Hepatol. 2007;5:339-44.

65. Nitzan O. Clostridium difficile and inflammatory bowel disease: role in pathogenesis and implications in treatment. World J Gastroeneterol. 2013;19:7577-85.
66. Gupta S, Allen-Vercoe E, Petrof EO. Fecal microbiota transplantation: in perspective. Therap Adv Gastroenterol. 2016;9:229-39.

67. Khoruts A, Rank KM, Newman KM, et al. Inflammatory bowel disease affects the outcome of fecal microbiota transplantation for recurrent Clostridium difficile infection. Clin Gastroenterol Hepatol. 2016; (In press, available online Feb 22, 2016).

68. Ben-Horin S, Margalit $M$, Bossuyt $P$, et al. Combination immunomodulator and antibiotic treatment in patients with inflammatory bowel disease and Clostridium difficile infection. Clin Gastroenterol Hepatol. 2009;7:981-7.

69. Jha V, Garcia-Garcia G, Iseki K, et al. Chronic kidney disease: global dimension and perspectives. Lancet. 2013;382:260-72.

70. Keddis MT, Khanna S, Noheria A, Baddour LM, Pardi DS, Qian Q. Clostridium difficile infection in patients with chronic kidney disease. Mayo Clin Proc. 2012;87:1046-53.

71. Phatharacharukul P, Thongprayoon C, Cheungpasitporn W, Edmonds PJ, Mahaparn P, Bruminhent J. The risks of incident and recurrent Clostridium difficile-associated diarrhea in chronic kidney disease and end-stage kidney disease patients: a systematic review and meta-analysis. Dig Dis Sci. 2015;60:2913-22.

72. Kim SC, Seo MY, Lee JY, et al. Advanced chronic kidney disease: a strong risk factor for Clostridium difficile infection. Korean J Intern Med. 2016;31:125-33.

73. Pant C, Deshpande A, Anderson MP, Sferra TJ. Clostridium difficile infection is associated with poor outcomes in end-stage renal disease. J Investig Med. 2012;60:529-32.

74. Thongprayoon C, Cheungpasitporn W, Phatharacharukul P, Mahaparn P, Bruminhent J. High mortality risk in chronic kidney disease and end stage kidney disease patients with Clostridium difficile infection: a systematic review and meta-analysis. J Nat Sci 2015; 1. Available in PMC April 13, 2015.

75. Kovithavongs T. Clostridium difficile colitis associated with chronic renal failure. Nephrol Dial Transplant. 1999;14:2256-7.

76. Thongprayoon C, Cheungpasitporn W, Phatharacharukul $\mathrm{P}$, et al. Chronic kidney disease and end-stage renal disease are risk factors for poor outcomes of Clostridium difficile infection: a systematic review and meta-analysis. Int J Clin Pract. 2015;69:998-1006. 
77. Do AN, Fridkin SK, Yechouron A, et al. Risk factors for early recurrent Clostridium difficile-associated diarrhea. Clin Infect Dis. 1998;26:954-9.

78. $\mathrm{Hu} \mathrm{MY}$, Katchar $\mathrm{K}$, Kyne $\mathrm{L}$, et al. Prospective derivation and validation of a clinical prediction rule for recurrent Clostridium difficile infection. Gastroenterology. 2009;136:1206-14.

79. D'Agostino RB, Collins SH, Pencina KM, Kean Y, Gorbach S. Risk estimation for recurrent Clostridium difficile rnfection based on clinical factors. Clin Infect Dis. 2014;58:1386-93.

80. Johnson S, Louie TJ, Gerding DN, et al. Vancomycin, metronidazole, or tolevamer for Clostridium difficile infection: results from two multinational, randomized, controlled trials. Clin Infect Dis. 2014;59:345-54.

81. Rao S, Kupfer Y, Pagala M, Chapnick E, Tessler S. Systemic absorption of oral vancomycin in patients with Clostridium difficile infection. Scand J Infect Dis. 2011;43:386-8.

82. Pogue JM, DePestel DD, Kaul DR, Khaled Y, Frame DG. Systemic absorption of oral vancomycin in a peripheral blood stem cell transplant patient with severe graft-versus-host disease of the gastrointestinal tract. Transplant Infect Dis. 2009;11:467-70.

83. Pettit NN, DePestel DD, Fohl AL, Eyler R, Carver PL. Risk factors for systemic vancomycin exposure following administration of oral vancomycin for the treatment of Clostridium difficile infection. Pharmacotherapy. 2015;35:119-26.

84. Mullane KM, Cornely OA, Crook DW, et al. Renal impairment and clinical outcomes of Clostridium difficile infection in two randomized trials. Am J Nephrol. 2013;38:1-11.

85. Rubio-Terres C, Cobo Reinoso J, Grau Cerrato S, et al. Economic assessment of fidaxomicin for the treatment of Clostridium difficile infection (CDI) in special populations (patients with cancer, concomitant antibiotic treatment or renal impairment) in Spain. Eur J Clin Microbiol Infect Dis. 2015;34:2213-23.

86. Sears P, Crook DW, Louie TJ, Miller MA, Weiss K. Fidaxomicin attains high fecal concentrations with minimal plasma concentrations following oral administration in patients with Clostridium difficile infection. Clin Infect Dis. 2012;55(Suppl 2):S116-20.

87. Tabaqchali S, O'Farrell S, Nash JQ, Wilks M. Vaginal carriage and neonatal acquisition of Clostridium difficile. J Med Microbiol. 1984;18:47-53.
88. Arsura EL, Fazio RA, Wickremesinghe PC. Pseudomembranous colitis following prophylactic antibiotic use in primary cesarean section. Am J Obstet Gynecol. 1985;151:87-9.

89. James AH, Katz VL, Dotters DJ, Rogers RG. Clostridium difficile infection in obstetric and gynecologic patients. South Med J. 1997;90:889-92.

90. Ghai S, Ghai V, Sunderji S. Fulminant postcesarean Clostridium difficile pseudomembranous colitis. Obstet Gynecol. 2007;109:541-3.

91. Centers for Disease Control and Prevention (CDC). Severe Clostridium difficile-associated disease in populations previously at low risk-four states. Morb Mortal Wkly Rep. 2005;2005(54):1201-5.

92. Rouphael NG, O'Donnell JA, Bhatnagar J, et al. Clostridium difficile-associated diarrhea: an emerging threat to pregnant women. Am J Obstet Gynecol. 2008;198(635):e1-6.

93. Kuntz JL, Yang M, Cavanaugh J, Saftlas AF, Polgreen PM. Trends in Clostridium difficile infection among peripartum women. Infect Control Hosp Epidemiol. 2010;31:532-4.

94. Unger JA, Whimbey E, Gravett MG, Eschenbach DA. The emergence of Clostridium difficile infection among peripartum women: a case-control study of a C. difficile outbreak on an obstetrical service. Infect Dis Obstet Gynecol. 2011;2011:267249-58.

95. Venugopal AA, Gerding DN, Johnson S. Clostridium difficile infection rates and spectrum of disease among peripartum women at one hospital from 2003 to 2007 with molecular typing analysis of recovered Clostridium difficile isolates. Am J Infecti Control. 2011;39:206-11.

96. Garey KW, Sethi S, Yadav Y, DuPont HL. Meta-analysis to assess risk factors for recurrent Clostridium difficile infection. J Hosp Infect. 2008;70:298-304.

97. Pant C, Deshpande A, Desai M, et al. Outcomes of Clostridium difficile infection in pediatric solid organ transplant recipients. Transpl Infect Dis. 2016;18:31-6.

98. Gupta A, Pardi DS, Baddour LM, Khanna S. Outcomes in children with Clostridium difficile infection: results from a nationwide survey. Gastroenterol Rep (Oxf). 2016. doi:10.1093/gastro/gow007

99. McFarland LV, Ozen M, Dinleyici EC, Goh S. Comparison of pediatric and adult antibiotic-associated diarrhea and Clostridium difficile infections. World $\mathrm{J}$ Gastroenterol. 2016;22:3078-128. 
100. González-Del Vecchio M, Álvarez-Uria A, Marin M, et al. Clinical significance of Clostridium difficile in children less than 2 years old. Pediatr Infect Dis J. 2016; 35:281-285.

101. Schutze GE, Willoughby RE. Committee on infectious diseases. Clostridium difficile infection in infants and children. Pediatrics. 2013;131:196-200.

102. Antonara S, Leber AL. Diagnosis of Clostridium difficile infections in children. J Clin Microbiol 2016; JCM.03014-15-38.

103. Hourigan SK, Sears CL, Oliva-Hemker M. Clostridium difficile infection in pediatric Inflammatory bowel disease. Inflamm Bowel Dis. 2016;22:1020-5.

104. Boyle NM, Magaret A, Stednick Z, et al. Evaluating risk factors for clostridium difficile infection in adult and pediatric hematopoietic cell transplant recipients. Antimicrob Resist Infect Control 2015; $1-11$.

105. Crews JD, Anderson LR, Waller DK, Swartz MD, DuPont HL, Starke JR. Risk factors for community-associated Clostridium difficile-associated diarrhea in children. Pediatr Infect Dis J. 2015;34:919-23.

106. Hourigan SK, Oliva-Hemker M. Fecal microbiota transplantation in children: a brief review. Pediatr Res. 2016;80:2-6.
107. Nicholson MR, Thomsen IP, Slaughter JC, Creech $\mathrm{CB}$, Edwards KM. Novel risk factors for recurrent Clostridium difficile infection in children. J Pediatr Gastroenterol Nutr. 2015;60:18-22.

108. Na JY, Park JM, Lee KS, Kang JO, Oh SH, Kim YJ. Clinical characteristics of symptomatic Clostridium difficile infection in children: conditions as infection risks and whether probiotics is effective. Pediatr Gastroenterol Hepatol Nutr. 2014;17:232-8.

109. Khanna S, Baddour LM, Huskins WC, et al. The epidemiology of Clostridium difficile infection in children: a population-based study. Clin Infect Dis. 2013;56:1401-6.

110. Pai S, Aliyu SH, Enoch DA, Karas JA. Five years experience of Clostridium difficile infection in children at a UK tertiary hospital: proposed criteria for diagnosis and management. PLoS ONE. 2012; 7:e51728.

111. Kim J, Shaklee JF, Smathers S, et al. Risk factors and outcomes associated with severe Clostridium difficile infection in children. Pediatr Infect Dis J. 2012;31:134-8.

112. Kelsen JR, Kim J, Latta D, et al. Recurrence rate of Clostridium difficile infection in hospitalized pediatric patients with inflammatory bowel disease. Inflamm Bowel Dis. 2011;17:50-5. 